\title{
A New Production Prediction Model Based on Taylor Expansion Formula
}

\author{
Xianfeng Ding $\mathbb{D}^{1},{ }^{1}$ Dan $Q \mathbf{Q} \mathbb{D}^{1}{ }^{1}$ and Haiyan Qiu ${ }^{2}$ \\ ${ }^{1}$ School of Science, Southwest Petroleum University, Cheng Du, Sichuan 610500, China \\ ${ }^{2}$ College of Chemistry and Chemical Engineering, Southwest Petroleum University, Cheng Du, Sichuan 610500, China \\ Correspondence should be addressed to Xianfeng Ding; fxxd@163.com
}

Received 28 May 2018; Revised 2 November 2018; Accepted 11 November 2018; Published 3 December 2018

Academic Editor: Mohamed Shaat

Copyright (c) 2018 Xianfeng Ding et al. This is an open access article distributed under the Creative Commons Attribution License, which permits unrestricted use, distribution, and reproduction in any medium, provided the original work is properly cited.

\begin{abstract}
On the basis of the analysis of the cumulative production growth curve model, the model variables are adjusted, and the Taylor formula is expanded on the adjusted model. Then the appropriate expansion order $n$ is selected, and the new model for the prediction of cumulative production is established. Furthermore, the error of the new model is discussed, and the model can theoretically achieve any given precision. The model can forecast oil and gas production, cumulative production, and recoverable reserves. Finally, the example analyses show that the greater the order number $(n)$ is, the smaller the error between the prediction data and the actual data and the greater the correlation coefficient become. Compared with other models, the results show that the model has higher prediction accuracy and wider application range and can be used to forecast the production of oil and gas field.
\end{abstract}

\section{Introduction}

For an engineer of oil and gas reservoir, oil and gas production, and recoverable reserves, prediction is an essential work, which is an important basis for oil and gas field planning and development, production allocation optimization, and daily dynamic analysis. The method of decline analysis is widely used which is based on system theory, fuzzy mathematics, information theory, grey theory, and cybernetics. Many studies had been focused on the production decline analysis. In 1945, Arps [1] proposed 4 types of declines: exponential, hyperbolic, harmonic, and ratio decline basing on decline trend observed in the field. Then Arps [2] (1956) simplified the proposed decline curves. In 1972, Gentry [3] studied the characteristics of each type of decline and then obtained two dimensionless equations and discussed the decline index $n$ in detail. Fetkovich [4] (1971 and 1980) constructed type curves combining the transient rate and the pseudo-steadystate decline curves and derived single-phase flow from material balance and Darcy law. Experts in China have also put forward some decline curves. In this respect, Yu and Chen are the representatives, and these are also empirical statistical formulas. In 1996, based on the distribution of $\chi^{2}$ in statistics, Chen [5] deduced the original Weng's prediction model systematically, obtained the generalized model for predicting oil and gas field production, maximum annual production, recoverable reserves, and their occurrence time, and proposed the linear trial and error method for solving the model. In 1997, Hu [6] first proposed the inverse tangent differential distribution model according to the theory of production decline of Arps. The production decline theory of Arps is further enriched. In 1999, Yu [7] presented two new types of decline curve $q_{t}=q_{i}(a+1) /\left(b^{t}+a\right)$ and $q_{t}=a /\left(t^{p}+b\right)^{q}$ and then demonstrated the validity of these two curves. On the basis of Weng's cycle model and Weibull's model, Song et al. [8] (2000) introduce a new model which can not only predict the oil and gas field production in the future, but also fix the time that the maximum annual production occurs in the recoverable cycle and put forward a geometric progression method to calculate parameters. In 2003, Li [9] improved Hu's antitangent differential distribution method, which made it more extensive. In 2004, Ding et al. [10] proposed a new model for predicting oil and gas field performance based on Weng's model, logistic model, and Chen-Hu prediction model. The model can predict recoverable reserves, cumulative production, and production. By changing the parameters of the model, the model can be simplified into logistic model and Chen-Hu prediction model. In 2005, Zhu et al. [11] put 
TABLE 1

\begin{tabular}{|c|c|}
\hline Prediction model & parameters \\
\hline$N_{\mathrm{p}}(t)=N_{\mathrm{R}} /\left(1+c e^{-\alpha t}\right)($ Chen, et al., 1996) [24] & $\begin{array}{c}N_{p}: \text { cumulative production of oil and gas fields, } 10^{4} t \text { (oil), } 10^{8} \mathrm{~m}^{3} \text { (gas) } \\
N_{R} \text { : Recoverable reserves of oil and gas fields, } 10^{4} t \text { (oil), } 10^{8} \mathrm{~m}^{3} \text { (gas) } \\
t \text { : development years, a; } \\
c \text { : model undetermined constant }\end{array}$ \\
\hline $\begin{array}{l}N_{\mathrm{p}}(t)=N_{\mathrm{R}} /\left(1+c e^{-\alpha t}\right) \\
(\mathrm{Hu}, \text { et al., 1997) }[25]\end{array}$ & $\begin{array}{c}N_{p}: \text { cumulative production of oil and gas fields, } 10^{4} t \text { (oil), } 10^{8} \mathrm{~m}^{3} \text { (gas) } \\
N_{R} \text { : Recoverable reserves of oil and gas fields, } 10^{4} t \text { (oil), } 10^{8} \mathrm{~m}^{3} \text { (gas) } \\
t \text { : development years, a; } \\
c, \alpha \text { : model undetermined constant }\end{array}$ \\
\hline $\begin{array}{l}N_{\mathrm{p}}(t)=N_{\mathrm{R}} t^{b} /\left(t^{b}+a\right) \\
N_{\mathrm{p}}(t)=N_{\mathrm{R}}\left(b^{t}-1\right) /\left(b^{t}+a\right)(\mathrm{Yu}, 2000)[26]\end{array}$ & $\begin{array}{c}N_{p} \text { : cumulative production of oil and gas fields, } 10^{4} t \text { (oil), } 10^{8} \mathrm{~m}^{3} \text { (gas) } \\
N_{R} \text { : Recoverable reserves of oil and gas fields, } 10^{4} t \text { (oil), } 10^{8} \mathrm{~m}^{3} \text { (gas) } \\
t \text { : development years, a; } \\
a, b \text { : model undetermined constant }\end{array}$ \\
\hline$N_{\mathrm{p}}(t)=N_{\mathrm{R}} /\left(1+c e^{-\alpha t} t^{-\beta}\right)($ Ding et al. 2004) [10] & $\begin{array}{c}N_{p}: \text { cumulative production of oil and gas fields, } 10^{4} t \text { (oil), } 10^{8} \mathrm{~m}^{3} \text { (gas) } \\
N_{R}: \text { Recoverable reserves of oil and gas fields, } 10^{4} t \text { (oil), } 10^{8} \mathrm{~m}^{3} \text { (gas) } \\
t \text { : development years, a; } \\
\mathcal{c}, \alpha, \beta \text { : model undetermined constant }\end{array}$ \\
\hline
\end{tabular}

forward a generalized production decline equation $q_{t}=$ $q_{i} /\left(a t^{2}+b t+1\right)^{1 / m}$, which can be transformed into Arps equation, tangent differential distribution production decline equation, and improved $\mathrm{Hu}$ decline equation by changing the parameters. In 2007, Yao et al. [12] analyzed oil and gas production in Tarim by the grey correlation degree method, and the influencing elements with higher relational degree were selected to establish nonlinear prediction model using grey theory $\mathrm{GM}(1, \mathrm{~N})$ to solve the model. The model is utilized to predict the oil production and achieved good results. There are many other kinds of oil and gas field production prediction methods, such as experience trend method, historical matching method [13](Zhou, 2012), mathematical model method [14-16](Saraiva et al., 2014; Li et al., 2013; Keven and Roland, 2007), the unit proven reserve ratio method, analogy method [17](Charpentier and Cook, 2010), and intelligent prediction method [18](Weiss et al., 2002).

In general, the reliability of prediction results not only depend on the accuracy of the information and data, the user's quality, and work experience, but also depend on the accuracy of the selected prediction methods and the established mathematical model. Among these factors, the most primary factor is the established mathematical model. Without appropriate forecasting method, it is impossible to have good prediction results. As we all know, Taylor formula is a very important formula in advanced mathematics and has been popular in prediction research and application [1923]. Based on the analysis of the cumulative production growth curve model, the model variables are adjusted and the adjusted model is expanded by the Taylor formula. Next, a new model for the prediction of cumulative production is established, which can be used to predict oil and gas production, cumulative production rate, and recoverable reserves.

\section{Methods}

2.1. Problem Description. The prediction of oil and gas production and recoverable reserves is a very important task in reservoir work. It is an important content in compiling oil and gas field development plan, designing oil and gas field development (adjustment) plan, and analyzing oil and gas field development performance. Although there are many production prediction models for oil and gas fields now and these models have been widely used in the prediction of oil or gas production and recoverable reserves, but there are still some limitations. In order to make each model complement each other, this article established a new model for predicting oil and gas field production, cumulative production, recoverable reserves, maximum annual gas production, and its occurrence time.

\subsection{The Prediction Model Based on Taylor Expansion Formula.} The cumulative growth curve models in the literatures are listed in Table 1.

These formulas of cumulative growth curve yield prediction model are based on the experience and then the formulas of oil field development are summarized, so the undetermined parameters in the formula must be attained through the actual data when solving the cumulative production and recoverable reserves.

Considering time $t$ is an incremental variable in the cumulative production model, when $t$ tends to infinity $(t \longrightarrow$ $\infty), t^{n}$ cannot be infinitely small. In order to facilitate the expansion of Taylor, we choose $1 / t$ as the variable; the above models turn to be the forms as follows:

$$
\begin{aligned}
& N_{\mathrm{p}}\left(\frac{1}{t}\right)=\frac{N_{\mathrm{R}}}{1+c t^{\beta}}, \\
& N_{\mathrm{p}}\left(\frac{1}{t}\right)=\frac{N_{\mathrm{R}} t^{-b}}{t^{-b}+a}, \\
& N_{\mathrm{p}}\left(\frac{1}{t}\right)=\frac{N_{\mathrm{R}}\left(b^{1 / t}-1\right)}{b^{1 / t}+a},
\end{aligned}
$$




$$
\begin{aligned}
N_{\mathrm{p}}\left(\frac{1}{t}\right) & =\frac{N_{\mathrm{R}}}{1+c e^{-\alpha / t}} \\
\text { and } N_{\mathrm{p}}\left(\frac{1}{t}\right) & =\frac{N_{\mathrm{R}}}{1+c e^{-\alpha / t} t^{\beta}}, \\
\qquad t & \\
t & =1,2, \cdots .
\end{aligned}
$$

The Taylor expansion formula of the function $f(x)$ at the point $x_{0}$ is as follows:

$$
\begin{aligned}
f(x)= & f\left(x_{0}\right)+f^{\prime}\left(x_{0}\right)\left(x-x_{0}\right)+\frac{f^{\prime \prime}\left(x_{0}\right)}{2 !}\left(x-x_{0}\right)^{2} \\
& +\cdots+\frac{f^{(n)}\left(x_{0}\right)}{n !}\left(x-x_{0}\right)^{n}+R_{n}(x)
\end{aligned}
$$

where $R_{n}(x)=\left(f^{(n+1)}(\xi) /(n+1) !\right)\left(x-x_{0}\right)^{n+1}$ and $\xi$ is a value between $x_{0}$ and $x$.

When $t$ tends to infinity, obviously $1 / t$ tends to zero. The cumulative production model with adjusted variables is expanded by the Taylor formula:

$$
\begin{aligned}
N_{\mathrm{p}}\left(\frac{1}{t}\right)= & N_{\mathrm{p}}(0)+N_{\mathrm{p}}^{\prime}(0) \frac{1}{t}+\frac{N_{\mathrm{p}}^{\prime \prime}(0)}{2 !}\left(\frac{1}{t}\right)^{2} \\
& +\frac{N_{\mathrm{p}}^{\prime \prime \prime}(0)}{3 !}\left(\frac{1}{t}\right)^{3}+\cdots+\frac{N_{\mathrm{p}}^{(n)}(0)}{n !}\left(\frac{1}{t}\right)^{n} \\
& +R_{n}\left(\frac{1}{t}\right)
\end{aligned}
$$

where $R_{n}(1 / t)=\left(N_{\mathrm{p}}{ }^{(n+1)}(\theta / t) /(n+1) !\right)(1 / t)^{n+1}, 0<\theta<$ $1, t=1,2, \cdots$, and $N_{\mathrm{p}}(0)$ is the recoverable reserve $\left(N_{\mathrm{R}}\right)$ when the original growth curve model as $t$ tends to infinity. Selecting the appropriate expansion order $n$, (3) could be used to predict the recoverable reserves.

Error Analysis. Using the expansion order $n$ of $N_{p}(1 / t)$ to calculate the cumulative production approximately, the error is

$$
R_{n}\left(\frac{1}{t}\right)=\frac{N_{\mathrm{p}}^{(n+1)}(\theta / t)}{(n+1) !}\left(\frac{1}{t}\right)^{n+1}
$$

For a fixed $n$, when $t \in(0,+\infty)$, if $\left|N_{\mathrm{p}}{ }^{(n+1)}(1 / t)\right| \leq M$, the error estimation equation is

$$
\left|R_{n}\left(\frac{1}{t}\right)\right|=\left|\frac{N_{\mathrm{p}}^{(n+1)}(\theta / t)}{(n+1) !}\left(\frac{1}{t}\right)^{n+1}\right| \leq \frac{M}{(n+1) !}\left(\frac{1}{t}\right)^{n+1}
$$

Given any precision $\varepsilon>0$ and choosing the appropriate time $t$, as long as $(M /(n+1) !)(1 / t)^{n+1} \leq \varepsilon$, the order $n$ can be achieved. This implies that, for any precision, a suitable expansion order $n$ can be found to ensure that the new prediction model is strictly true.

When $t$ tends to infinity, $R_{n}(1 / t)=\left(N_{\mathrm{p}}^{(n+1)}(\theta / t) /(n+\right.$ $1) !)(1 / t)^{n+1}$ is a higher order infinitesimal of $(1 / t)^{n}$. Therefore, the remainder can be written as

$$
R_{n}\left(\frac{1}{t}\right)=o\left[\left(\frac{1}{t}\right)^{n}\right]
$$

When $n=2, N_{\mathrm{p}}(1 / t)=N_{\mathrm{p}}(0)+N_{\mathrm{p}}^{\prime}(0)(1 / t)+\left(N_{\mathrm{p}}^{\prime \prime}(0) /\right.$ $2 !)(1 / t)^{2}+o\left[(1 / t)^{2}\right]$, ignoring the infinite small terms, the above equation can be written as

$$
N_{\mathrm{p}}\left(\frac{1}{t}\right)=a+b \frac{1}{t}+c\left(\frac{1}{t}\right)^{2}
$$

where $a, b, c$ are undetermined parameters. Equation (7) can be solved by regression analysis, and then it can be used to predict the cumulative production.

When

$$
\begin{aligned}
n= & 3 \\
N_{\mathrm{p}}\left(\frac{1}{t}\right)= & N_{\mathrm{p}}(0)+N_{\mathrm{p}}^{\prime}(0) \frac{1}{t}+\frac{N_{\mathrm{p}}^{\prime \prime}(0)}{2 !}\left(\frac{1}{t}\right)^{2} \\
& +\frac{N_{\mathrm{p}}^{\prime \prime \prime}(0)}{3 !}\left(\frac{1}{t}\right)^{3}+o\left[\left(\frac{1}{t}\right)^{3}\right]
\end{aligned}
$$

ignoring the infinite small items, the above equation can be written as

$$
N_{\mathrm{p}}\left(\frac{1}{t}\right)=a+b \frac{1}{t}+c\left(\frac{1}{t}\right)^{2}+d\left(\frac{1}{t}\right)^{3}
$$

where $a, b, c, d$ are undetermined parameters. They can be solved by regression analysis, and then it can predict the cumulative production.

Let

$$
\begin{aligned}
\bar{Y} & =N_{\mathrm{p}}\left(\frac{1}{t}\right), \\
X_{1} & =\frac{1}{t}, \\
X_{2} & =\left(\frac{1}{t}\right)^{2}, \\
X_{3} & =\left(\frac{1}{t}\right)^{3}, \\
Y & =N_{\mathrm{p}}(t), \\
t & =1, \cdots, m,
\end{aligned}
$$

then (9) can be written as

$$
\bar{Y}=a+b X_{1}+c X_{2}+d X_{3}
$$

When different values are taken by $t$, the error sum of square between predicted data and the actual data can be written as

$$
\begin{aligned}
E & =\sum_{t=1}^{m}(Y(t)-\bar{Y}(t))^{2} \\
& =\sum_{t=1}^{m}\left[Y(t)-a-b X_{1}(t)-c X_{2}(t)-d X_{3}(t)\right]^{2}
\end{aligned}
$$

For obtaining the optimal coefficient $a, b, c, d$, we must make a minimum error $E$; that is, 


$$
\begin{aligned}
\min E & =\sum_{t=1}^{m}(Y(t)-\bar{Y}(t))^{2} \\
& =\sum_{t=1}^{m}\left[Y(t)-a-b X_{1}(t)-c X_{2}(t)-d X_{3}(t)\right]^{2}
\end{aligned}
$$

Let the partial derivatives of (13) with respect to $a, b, c, d$ be zero; then we can get the linear equation set (14).

$$
\begin{aligned}
& m a+b \sum_{t=1}^{m} X_{1}(t)+c \sum_{t=1}^{m} X_{2}(t)+d \sum_{t=1}^{m} X_{3}(t)=\sum_{t=1}^{m} Y(t) \\
& a \sum_{t=1}^{m} X_{1}(t)+b \sum_{t=1}^{m} X_{1}^{2}(t)+c \sum_{t=1}^{m} X_{1}(t) X_{2}(t) \\
& +d \sum_{t=1}^{m} X_{1}(t) X_{3}(t)=\sum_{t=1}^{m} X_{1}(t) Y(t) \\
& a \sum_{t=1}^{m} X_{2}(t)+b \sum_{t=1}^{m} X_{1}(t) X_{2}(t)+c \sum_{t=1}^{m} X_{2}^{2}(t) \\
& +d \sum_{t=1}^{m} X_{2}(t) X_{3}(t)=\sum_{t=1}^{m} X_{2}(t) Y(t) \\
& a \sum_{t=1}^{m} X_{3}(t)+b \sum_{t=1}^{m} X_{1}(t) X_{3}(t)+c \sum_{t=1}^{m} X_{2}(t) X_{3}(t) \\
& \quad+d \sum_{t=1}^{m} X_{3}^{2}(t)=\sum_{t=1}^{m} X_{3}(t) Y(t)
\end{aligned}
$$

The solution of (14) is the value of the coefficient $a, b, c, d$, and so on, until we find the appropriate order $n$ in (15) to make the predicted results well in accordance with the actual data. Therefore, the following equation can estimate cumulative production and recoverable reserves.

$$
\begin{aligned}
N_{\mathrm{p}}\left(\frac{1}{t}\right)= & a_{0}+a_{1} \frac{1}{t}+a_{2}\left(\frac{1}{t}\right)^{2}+a_{3}\left(\frac{1}{t}\right)^{3}+\cdots \\
& +a_{n}\left(\frac{1}{t}\right)^{n}
\end{aligned}
$$

where $a_{0}, a_{1}, \cdots, a_{n}$ are undetermined parameters.

For the calculation of production, the method in literature (Ding et al., 2004) can be adopted. That is,

$$
q(t)=N_{\mathrm{p}}(t)-N_{\mathrm{p}}(t-1)
$$

If the actual data is daily production, we can predict cumulative daily production and daily production by (15) and (16).

2.3. Model Validation. When using our proposed formula (15) to predict accumulative production and recoverable reserves, we need to solve the unknown parameters in the formula, and the regression analysis method is used here. In order to determine the appropriate $n$, regression analysis was carried out to obtain the parameters according to the actual data, which obtained the only certain Taylor expansion. To further validate the applicability of this model, we use the Taylor expansion formula of the production prediction model proposed in the paper [27].
2.3.1. Logistic Production Prediction Model. Logistic production prediction model is $N_{\mathrm{p}}(t)=N_{\mathrm{R}} /\left(1+c e^{-\alpha t}\right)$. We choose $1 / t$ as the variable, $N_{\mathrm{p}}(1 / t)=N_{\mathrm{R}} /\left(1+c e^{-\alpha(1 / t)^{-1}}\right)=N_{\mathrm{R}} /(1+$ $c e^{-\alpha t}$ ) (the cumulative production of $t$ year); Taylor expansion formula is

$$
\begin{aligned}
N_{\mathrm{p}}\left(\frac{1}{t}\right)= & N_{\mathrm{p}}(0)+N_{\mathrm{p}}^{\prime}(0) \frac{1}{t}+\frac{N_{\mathrm{p}}^{\prime \prime}(0)}{2 !}\left(\frac{1}{t}\right)^{2} \\
& +\frac{N_{\mathrm{p}}^{\prime \prime \prime}(0)}{3 !}\left(\frac{1}{t}\right)^{3}+\cdots+\frac{N_{\mathrm{p}}^{(n)}(0)}{n !}\left(\frac{1}{t}\right)^{n} \\
& +R_{n}\left(\frac{1}{t}\right)
\end{aligned}
$$

We can ignore the infinite item:

$$
\begin{aligned}
N_{\mathrm{p}}\left(\frac{1}{t}\right)= & a_{0}+a_{1} \frac{1}{t}+a_{2}\left(\frac{1}{t}\right)^{2}+a_{3}\left(\frac{1}{t}\right)^{3}+\cdots \\
& +a_{n}\left(\frac{1}{t}\right)^{n} .
\end{aligned}
$$

For $t \longrightarrow \infty, a_{0}=N_{R}$, the recoverable reserves are equal to the cumulative production at this time.

The model parameters are obtained by self-regression in [19], and the results are $\alpha=-\ln \beta, N_{R}=(1-\beta) / \alpha, c=$ $\left(N_{R} / N_{P}-1\right) e^{\alpha t}, c=(1 / m) \sum_{j=1}^{m}\left(N_{R} / N_{p j}-1\right) e^{\alpha t_{j}}$ (considering the influences on the parameter $c$, taking the average); the linear regression between the cumulative yield and time is used to obtain the slope of the straight line. Bring in actual data: $\alpha=-\ln 0.8027=0.2198, N_{R}=(1-0.8027) /(3.0479 \times$ $\left.10^{-5}\right)=6473\left(10^{4} t\right), c=22.2072$.

We choose $1 / t$ as the variable; the Logistic production prediction model turns to be the forms

$$
N_{\mathrm{p}}\left(\frac{1}{t}\right)=\frac{6473}{1+22.2072 e^{-0.2198 / t}} .
$$

When $\mathrm{n}=2, \mathrm{n}=3, \mathrm{n}=4, \mathrm{n}=5$, and $\mathrm{n}=7$, Taylor expansion formula is used to predict the cumulative production in different years, and the results are shown in Table 7.

2.3.2. GひH Production Prediction Model. To further verify the effectiveness of this model, we use the proposed model in [28], which can be simplified as the famous Gompertz model and the Herbert model. So the model is referred to as the $\mathrm{G} \& \mathrm{H}$ yield prediction model. G\&H production prediction model is $N_{\mathrm{p}}(t)=A_{2} e^{B_{2} e^{-b t}}$ (the cumulative production of $\mathrm{t}$ year). We choose $1 / t$ as the variable:

$$
N_{\mathrm{p}}\left(\frac{1}{t}\right)=A_{2} e^{B_{2} e^{-b(1 / t)^{-1}}}=A_{2} e^{B_{2} e^{-b t}}
$$

(Cumulative production of the year $t$ ) 


$$
\begin{aligned}
N_{\mathrm{p}}\left(\frac{1}{t}\right)= & N_{\mathrm{p}}(0)+N_{\mathrm{p}}^{\prime}(0) \frac{1}{t}+\frac{N_{\mathrm{p}}^{\prime \prime}(0)}{2 !}\left(\frac{1}{t}\right)^{2} \\
& +\frac{N_{\mathrm{p}}^{\prime \prime \prime}(0)}{3 !}\left(\frac{1}{t}\right)^{3}+\cdots+\frac{N_{\mathrm{p}}^{(n)}(0)}{n !}\left(\frac{1}{t}\right)^{n} \\
& +R_{n}\left(\frac{1}{t}\right)
\end{aligned}
$$

We can ignore the infinite item:

$$
\begin{aligned}
N_{\mathrm{p}}\left(\frac{1}{t}\right)= & a_{0}+a_{1} \frac{1}{t}+a_{2}\left(\frac{1}{t}\right)^{2}+a_{3}\left(\frac{1}{t}\right)^{3}+\cdots \\
& +a_{n}\left(\frac{1}{t}\right)^{n}
\end{aligned}
$$

For $t \longrightarrow \infty, a_{0}=N_{R}$. The model parameters are obtained by linear regression in [28], and the results are $A_{2}=6621$, $B_{2}=-7.1279, b=0.1647$.

We choose $1 / t$ as the variable; the G\&H production prediction model turns to be the forms

$$
N_{\mathrm{p}}\left(\frac{1}{t}\right)=6621 e^{-7.1279 e^{-0.1647 t}}
$$

When $\mathrm{n}=2, \mathrm{n}=3, \mathrm{n}=4, \mathrm{n}=5$, and $\mathrm{n}=7$, Taylor expansion formula is used to predict the cumulative production in different years, and the results are presented at Table 8 .

2.3.3. Comparison. Table 9 is the prediction results of the proposed Taylor expansion model $(\mathrm{T})$ and the prediction results of Taylor expansion of logistic model (L) and G\&H model $(G \& H)$. We compare a smaller order of $n=2$ and larger order of $n=7$. The comparison of actual data and predicted data of cumulative production are shown in Figures 1 and 2.

Figure 1 or Figure 2 can explain that the Taylor model predicts more accurately when compared with the logistic model and Gompertz model and the Herbert model. Comparing Figure 1 and Figure 2, we can conclude that the obtained results by Taylor prediction model are closer to the real value as the increase of Taylor expansion order. Table 9 is the error of prediction value and the real value. Next we give the definition of error. Let $x$ and $y$ be prediction value and real value, respectively. The error is defined by $(x-y) / y$. Tables 9 and 10 show that the effect of prediction reduced over time when Taylor's order is certain and that the effect of prediction increased over time when the time is certain. Using the proposed Taylor expansion model $(\mathrm{T})$ and the Taylor expansion of logistic model (L) and G\&H model $(\mathrm{G} \& \mathrm{H})$ to predict recoverable reserves, the error is around 5\% in the first 10 years. This forecast error is reasonable, because different models exit minor difference. Although the effect of the latter is not particularly good, on the whole, we can draw the conclusion that the proposed prediction model based on Taylor expansion is feasible.

2.3.4. Correlation Analysis. The results of the three kinds of Taylor expansion of different models are compared when $\mathrm{n}=2$ and $\mathrm{n}=7$, respectively, and the results are represented

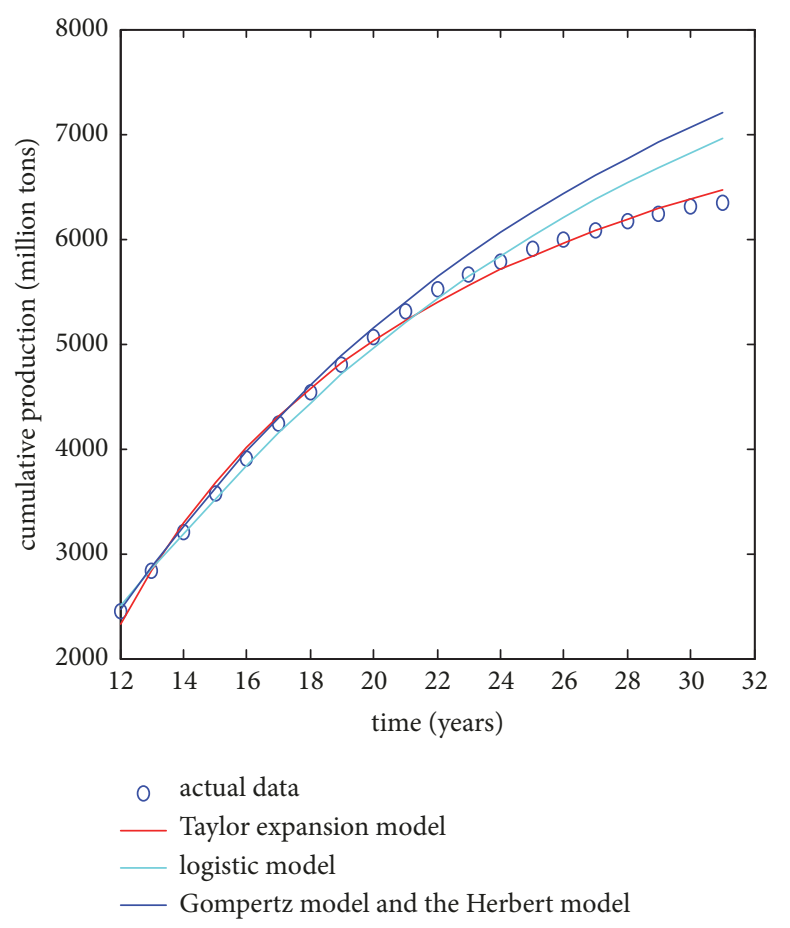

Figure 1: The actual data and the prediction data of the three models.

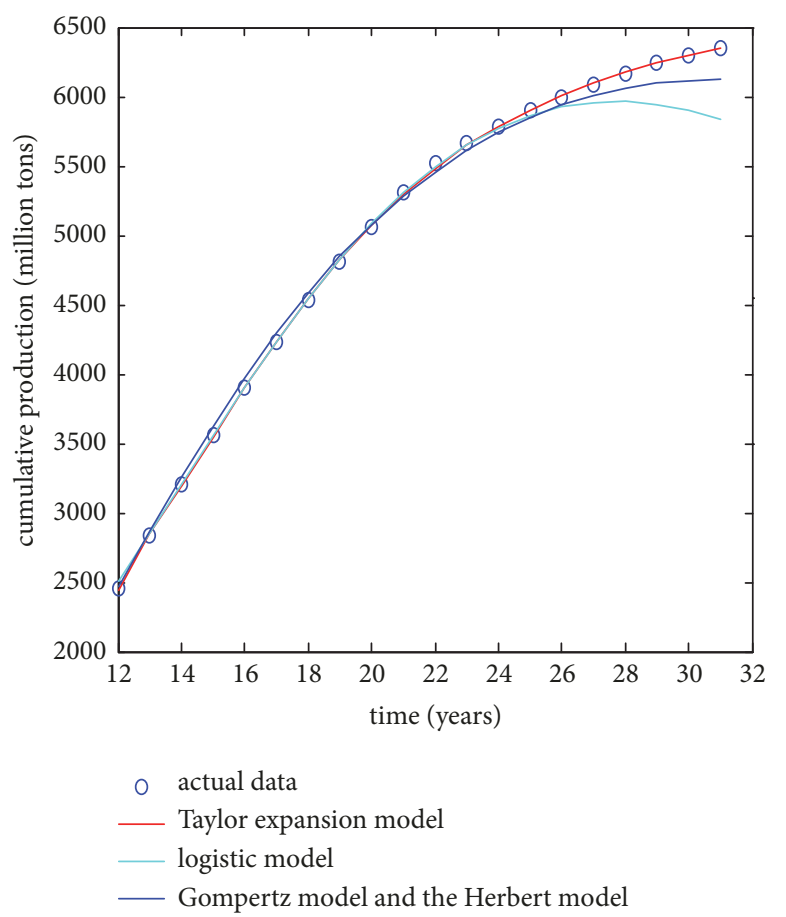

FIGURE 2: The actual data and the prediction data of the three models.

by a matrix. The elements of the matrix represent the correlation coefficient of sequence $\mathrm{X}$ and sequence $\mathrm{Y}$, the result is a $2 * 2$ matrix, the diagonal elements represent $X$ and $\mathrm{Y}$ autocorrelation, and nondiagonal elements represent the 
correlation coefficient of $\mathrm{X}$ and $\mathrm{Y}$ and $\mathrm{Y}$ and $\mathrm{X}$, two of which are equal. The results are as follows:

$$
\begin{aligned}
& \mathrm{n}=2: \\
& A=\left(\begin{array}{ll}
1.0000 & 0.9933 \\
0.9933 & 1.0000
\end{array}\right), \\
& B=\left(\begin{array}{ll}
1.0000 & 0.9951 \\
0.9951 & 1.0000
\end{array}\right) \\
& \mathrm{n}=7: \\
& C=\left(\begin{array}{ll}
1.0000 & 0.9945 \\
0.9945 & 1.0000
\end{array}\right), \\
& D=\left(\begin{array}{ll}
1.0000 & 0.9991 \\
0.9991 & 1.0000
\end{array}\right)
\end{aligned}
$$

The correlation coefficient matrices $\mathrm{A}, \mathrm{C}$ present the prediction results of Taylor expansion prediction model and the Taylor expansion of logistic model, respectively. The correlation coefficient matrices $\mathrm{B}, \mathrm{D}$ present the prediction results of Taylor expansion prediction model and the Taylor expansion of G\&H model, respectively. According to the correlation coefficient matrix, the values become closer to 1. The cumulative production predicted by this method is consistent with the other two Taylor expansion models. It shows that the prediction model established in this paper is practical and reliable.

2.4. The Novelty of Model. Compared with other models in the literatures, the Taylor model has two distinct advantages.

(1) It can be applied to forecast the production of oil and gas fields. We can predict cumulative annual production and daily production by (15) and (16). And as time goes on, $1 / t$ of (15) closes to 0 and results predicted by the model are more accurate. As the expansion order $n$ increases, the prediction error becomes smaller and smaller, and the correlation coefficient between the predicted value and the actual value becomes larger and larger.

(2) Taylor model is a power function in nature. Compared with other models which are containing exponential function, it is faster in calculation speed and occupies less CPU, so it is more suitable for oil and gas production prediction.

\section{Result and Discussion}

3.1. Application of Prediction Model. To demonstrate the scalability of our model, the experiments were conducted on oilfield block of Hudson oilfield in Tarim China and Bavly oilfield in this part. The Bavly oilfield was discovered in 1946 and developed in 1950, which is one of the outer edge waterflooding sandstone oilfields in the Soviet Union, developed with keeping the formation pressure. The oil bearing area of the oilfield is $118 \mathrm{~km}^{2}$. The block was formally put into development in August 2000. The block's month cumulative production from January 2004 to July 2013 was calculated by

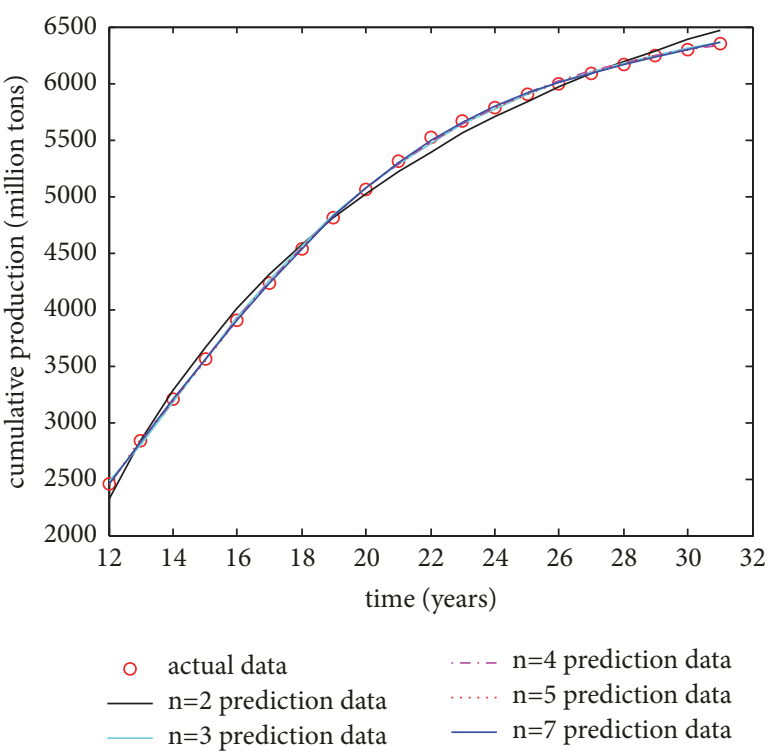

FIgURE 3: The actual data and the prediction data of the cumulative production of Bavly oilfield.

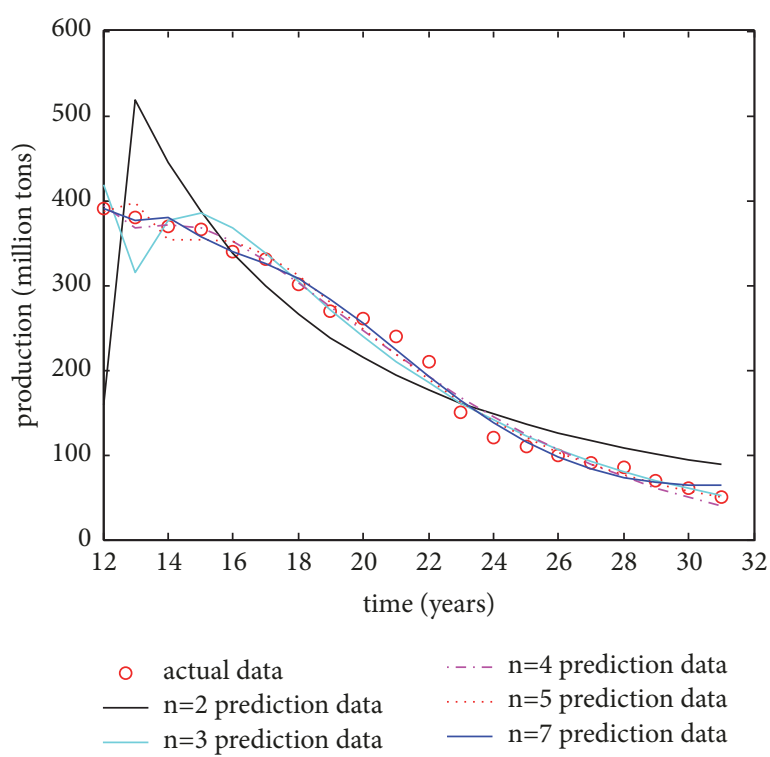

FIgURE 4: The actual data and the prediction data of the annual production of Bavly oilfield.

our model and comparison and analysis were made between the prediction data by models in literatures and the actual data.

\subsection{Numerical Results}

3.2.1. Bavly Oilfield. The practical data and the prediction data of the cumulative production and production are shown in Figures 3 and 4 and Tables 5 and 6, respectively. Recoverable reserves are shown in Table 2 and the correlation coefficient of the prediction data and the practical data is shown in Table 3. 
TABLE 2: Cumulative recoverable reserves of Bavly oilfield (million tons).

\begin{tabular}{lccccc}
\hline expansion order & $\mathrm{n}=4$ & $\mathrm{n}=5$ & $\mathrm{n}=7$ & $\mathrm{n}=20$ & $\mathrm{n}=50$ \\
\hline recoverable reserves & 1252.071953 & 10282.45991 & 66452.93302 & 66452.93302 & 66452.93301 \\
\hline
\end{tabular}

TABLE 3: The correlation coefficient of the prediction data and the actual data of Bavly oilfield.

\begin{tabular}{lccccc}
\hline expansion order & $\mathrm{n}=2$ & $\mathrm{n}=3$ & $\mathrm{n}=4$ & $\mathrm{n}=5$ & $\mathrm{n}=7$ \\
\hline correlation coefficient & 0.9979 & 0.9998 & 0.999917099 & 0.999944399 & 0.999970846 \\
\hline
\end{tabular}

TABLE 4: The correlation coefficient and recoverable reserves of a block of Hudson oilfield.

\begin{tabular}{lcccc}
\hline & $\mathrm{n}=5$ & $\mathrm{n}=6$ & in ref. Chen et al. 1996 & in ref. Ding et al. 2004 \\
\hline correlation coefficient & 0.999951 & 0.999985 & 0.999865 & 0.999898 \\
\hline recoverable reserves (million tons) & 4001.015 & 3111.262 & 3000 & 3000 \\
\hline
\end{tabular}

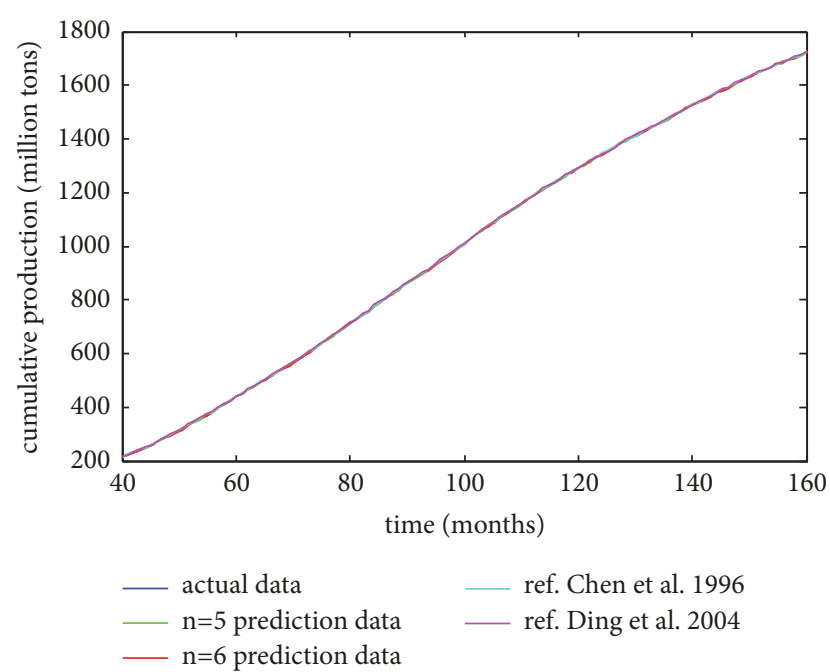

FIGURE 5: The comparison of actual and predicted data of cumulative production.

It follows from Tables 2 and 3 that the prediction data is very close to the practical data of the field development. With the increase of the expansion order $n$, there are no major changes for the prediction data of recoverable reserves, and the correlation coefficient is gradually approximating close to 1. Furthermore, these data are also quietly close to the prediction data in the literatures.

3.2.2. An Oilfield Block of Hudson Oilfield in Tarim China. The comparison of actual data and predicted data of month cumulative production and production are shown in Figures 5,6 , and 7 and the comparison of recoverable reserves is shown in Table 4.

Figures 5, 6, and 7 and Table 4 displayed that the new model has higher prediction accuracy compared with the other models in the literatures. Therefore, it can be used to forecast the actual oil and gas production.

\section{Conclusions}

(1) Based on the analysis of the cumulative production growth curve model and the Taylor expansion of the model, once

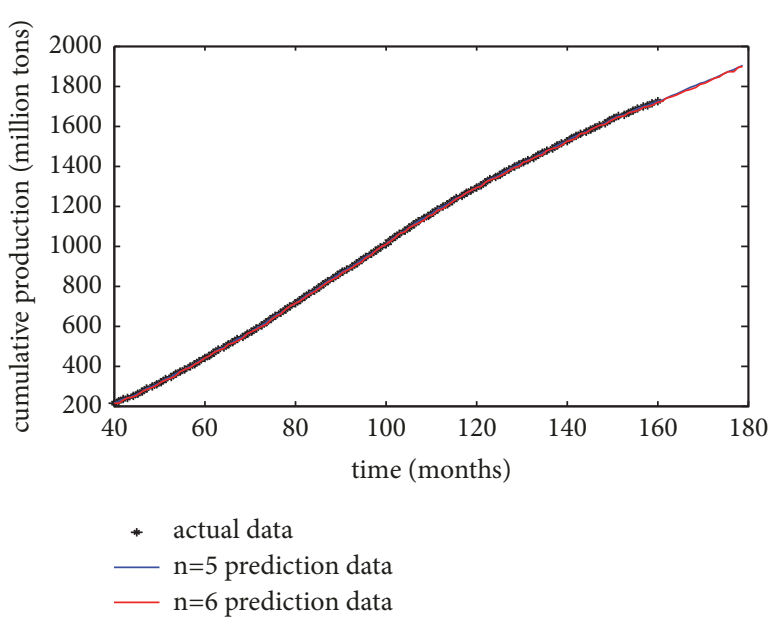

FIGURE 6: The comparison of actual and predicted data of cumulative production.

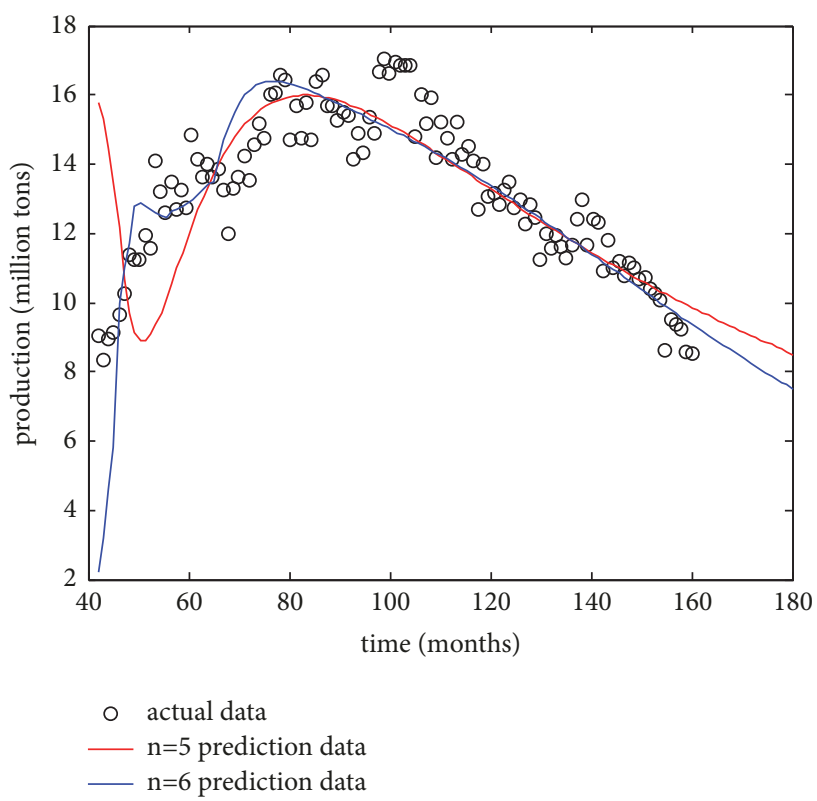

FIGURE 7: The comparison of actual and predicted data of production. 
TABLE 5: The actual data and the prediction data of the cumulative production of Bavly [10] oilfield.

\begin{tabular}{|c|c|c|c|c|c|c|c|}
\hline \multirow{2}{*}{ year } & \multirow{2}{*}{$\mathrm{t}(\mathrm{a})$} & \multicolumn{6}{|c|}{ cumulative production (million tons) } \\
\hline & & practical data & prediction data $\mathrm{n}=2$ & prediction data $\mathrm{n}=3$ & prediction data $n=4$ & prediction data $n=5$ & prediction data $n=7$ \\
\hline 1959 & 12 & 2450 & 2318.789 & 2478.5996 & 2454.5865 & 2446.3177 & 2450.3951 \\
\hline 1960 & 13 & 2830 & 2836.9906 & 2793.9021 & 2822.8706 & 2843.0266 & 2827.0884 \\
\hline 1961 & 14 & 3200 & 3281.8253 & 3171.0607 & 3194.672 & 3195.8839 & 3206.4152 \\
\hline 1962 & 15 & 3565 & 3667.8429 & 3556.2227 & 3561.4828 & 3549.8524 & 3562.595 \\
\hline 1963 & 16 & 3905 & 4005.9848 & 3923.4511 & 3913.4051 & 3900.8663 & 3902.4385 \\
\hline 1964 & 17 & 4235 & 4304.637 & 4261.2805 & 4243.0933 & 4236.546 & 4228.1552 \\
\hline 1965 & 18 & 4535 & 4570.3352 & 4565.7695 & 4546.1807 & 4547.2328 & 4535.8497 \\
\hline 1966 & 19 & 4805 & 4808.2484 & 4836.8296 & 4820.7178 & 4827.7119 & 4819.6946 \\
\hline 1967 & 20 & 5065 & 5022.5182 & 5076.2599 & 5066.4659 & 5076.3844 & 5074.9303 \\
\hline 1968 & 21 & 5305 & 5216.5021 & 5286.6897 & 5284.2989 & 5294.047 & 5299.0852 \\
\hline 1969 & 22 & 5515 & 5392.9507 & 5471.0127 & 5475.7569 & 5482.8775 & 5492.0571 \\
\hline 1970 & 23 & 5665 & 5554.1387 & 5632.0934 & 5642.7353 & 5645.7241 & 5655.6689 \\
\hline 1971 & 24 & 5785 & 5701.9639 & 5772.6209 & 5787.2774 & 5785.6499 & 5793.0743 \\
\hline 1972 & 25 & 5895 & 5838.0216 & 5895.0469 & 5911.4414 & 5905.6629 & 5908.201 \\
\hline 1973 & 26 & 5995 & 5963.6633 & 6001.5667 & 6017.2188 & 6008.568 & 6005.3019 \\
\hline 1974 & 27 & 6085 & 6080.0409 & 6094.1253 & 6106.4878 & 6096.8977 & 6088.6276 \\
\hline 1975 & 28 & 6170 & 6188.1426 & 6174.4338 & 6180.9887 & 6172.8895 & 6162.2078 \\
\hline 1976 & 29 & 6240 & 6288.8208 & 6243.9918 & 6242.3153 & 6238.4913 & 6229.7177 \\
\hline 1977 & 30 & 6300 & 6382.8148 & 6304.1099 & 6291.9142 & 6295.3804 & 6294.4093 \\
\hline 1978 & 31 & 6350 & 6470.7689 & 6355.933 & 6331.0909 & 6344.9897 & 6359.0873 \\
\hline
\end{tabular}

TABLE 6: The actual data and the prediction data of the annual production of Bavly oilfield [10].

\begin{tabular}{|c|c|c|c|c|c|c|c|}
\hline \multirow{2}{*}{ year } & \multirow{2}{*}{$\mathrm{t}(\mathrm{a})$} & \multicolumn{6}{|c|}{ annual production (million tons) } \\
\hline & & actual data & prediction data $\mathrm{n}=2$ & prediction data $\mathrm{n}=3$ & prediction data $n=4$ & prediction data $\mathrm{n}=5$ & prediction data $\mathrm{n}=7$ \\
\hline 1959 & 12 & 390 & 158.789 & 418.5996 & 394.5865 & 386.3177 & 390.3951 \\
\hline 1960 & 13 & 380 & 518.2016 & 315.3025 & 368.2841 & 396.7089 & 376.6933 \\
\hline 1961 & 14 & 370 & 444.8347 & 377.1586 & 371.8014 & 352.8573 & 379.3268 \\
\hline 1962 & 15 & 365 & 386.0176 & 385.162 & 366.8108 & 353.9685 & 356.1798 \\
\hline 1963 & 16 & 340 & 338.1419 & 367.2284 & 351.9223 & 351.0139 & 339.8435 \\
\hline 1964 & 17 & 330 & 298.6522 & 337.8294 & 329.6882 & 335.6797 & 325.7167 \\
\hline 1965 & 18 & 300 & 265.6982 & 304.489 & 303.0874 & 310.6868 & 307.6945 \\
\hline 1966 & 19 & 270 & 237.9132 & 271.0601 & 274.5371 & 280.4791 & 283.8449 \\
\hline 1967 & 20 & 260 & 214.2698 & 239.4303 & 245.7481 & 248.6725 & 255.2357 \\
\hline 1968 & 21 & 240 & 193.9839 & 210.4298 & 217.833 & 217.6626 & 224.1549 \\
\hline 1969 & 22 & 210 & 176.4486 & 184.323 & 191.458 & 188.8305 & 192.9719 \\
\hline 1970 & 23 & 150 & 161.188 & 161.0807 & 166.9784 & 162.8466 & 163.6118 \\
\hline 1971 & 24 & 120 & 147.8252 & 140.5275 & 144.5421 & 139.9258 & 137.4054 \\
\hline 1972 & 25 & 110 & 136.0577 & 122.426 & 124.164 & 120.013 & 115.1267 \\
\hline 1973 & 26 & 100 & 125.6417 & 106.5198 & 105.7774 & 102.9051 & 97.1009 \\
\hline 1974 & 27 & 90 & 116.3776 & 92.5586 & 89.269 & 88.3297 & 83.3257 \\
\hline 1975 & 28 & 85 & 108.1017 & 80.3085 & 74.5009 & 75.9918 & 73.5802 \\
\hline 1976 & 29 & 70 & 100.6782 & 69.558 & 61.3266 & 65.6018 & 67.5099 \\
\hline 1977 & 30 & 60 & 93.994 & 60.1181 & 49.5989 & 56.8891 & 64.6916 \\
\hline 1978 & 31 & 50 & 87.9541 & 51.8231 & 39.1767 & 49.6093 & 64.678 \\
\hline
\end{tabular}


TABLE 7: The actual data and the prediction data of the cumulative production of Bavly [10] oilfield.

\begin{tabular}{|c|c|c|c|c|c|c|c|}
\hline \multirow{2}{*}{ year } & \multirow{2}{*}{$\mathrm{t}(\mathrm{a})$} & \multicolumn{6}{|c|}{ cumulative production (million tons) } \\
\hline & & practical data & prediction data $n=2$ & prediction data $n=3$ & prediction data $n=4$ & prediction data $n=5$ & prediction data $n=7$ \\
\hline 1959 & 12 & 2450 & 2500.6 & 2500.6 & 2500.6 & 2500.6 & 2500.6 \\
\hline 1960 & 13 & 2830 & 2843.1 & 2845.2 & 2845.2 & 2845.2 & 2845.2 \\
\hline 1961 & 14 & 3200 & 3186.2 & 3199.3 & 3199.5 & 3199.1 & 3198.9 \\
\hline 1962 & 15 & 3565 & 3520.6 & 3556.6 & 3557.3 & 3555.0 & 3553.6 \\
\hline 1963 & 16 & 3905 & 3841.4 & 3911.6 & 3913.3 & 3906.3 & 3900.9 \\
\hline 1964 & 17 & 4235 & 4146.3 & 4260.5 & 4263.9 & 4248.1 & 4233.2 \\
\hline 1965 & 18 & 4535 & 4434.4 & 4600.8 & 4606.3 & 4576.8 & 4544.1 \\
\hline 1966 & 19 & 4805 & 4706.0 & 4930.7 & 4938.8 & 4890.3 & 4828.6 \\
\hline 1967 & 20 & 5065 & 4961.5 & 5249.0 & 5260.3 & 5187.1 & 5083.2 \\
\hline 1968 & 21 & 5305 & 5201.7 & 5555.3 & 5570.3 & 5466.8 & 5305.6 \\
\hline 1969 & 22 & 5515 & 5427.5 & 5849.4 & 5868.3 & 5729.5 & 5494.9 \\
\hline 1970 & 23 & 5665 & 5639.9 & 6131.3 & 6154.5 & 5975.5 & 5650.8 \\
\hline 1971 & 24 & 5785 & 5839.8 & 6401.3 & 6429.0 & 6205.4 & 5773.9 \\
\hline 1972 & 25 & 5895 & 6028.1 & 6659.7 & 6692.1 & 6420.1 & 5865.2 \\
\hline 1973 & 26 & 5995 & 6205.6 & 6907.0 & 6944.2 & 6620.3 & 5926.1 \\
\hline 1974 & 27 & 6085 & 6373.2 & 71435 & 7185.6 & 6807.0 & 5958.4 \\
\hline 1975 & 28 & 6170 & 6531.6 & 7369.8 & 7417.0 & 6981.1 & 5963.7 \\
\hline 1976 & 29 & 6240 & 6681.4 & 7586.3 & 7638.6 & 7143.4 & 5944.1 \\
\hline 1977 & 30 & 6300 & 6823.3 & 7793.6 & 7851.0 & 7294.7 & 5901.4 \\
\hline 1978 & 31 & 6350 & 6957.9 & 7992.2 & 8054.5 & 7435.9 & 5837.5 \\
\hline
\end{tabular}

TABLE 8: The actual data and the prediction data of the cumulative production of Bavly [10] oilfield.

\begin{tabular}{|c|c|c|c|c|c|c|c|}
\hline \multirow{2}{*}{ year } & \multirow{2}{*}{$\mathrm{t}(\mathrm{a})$} & \multicolumn{6}{|c|}{ cumulative production (million tons) } \\
\hline & & practical data & prediction data $\mathrm{n}=2$ & prediction data $\mathrm{n}=3$ & prediction data $\mathrm{n}=4$ & prediction data $\mathrm{n}=5$ & prediction data $\mathrm{n}=7$ \\
\hline 1959 & 12 & 2450 & 2465.9 & 2465.9 & 2465.9 & 2465.9 & 2465.9 \\
\hline 1960 & 13 & 2830 & 2864.3 & 2865.0 & 2864.9 & 2864.9 & 2864.9 \\
\hline 1961 & 14 & 3200 & 3250.6 & 3255.3 & 3254.0 & 3253.6 & 3253.5 \\
\hline 1962 & 15 & 3565 & 3618.8 & 3631.6 & 3626.7 & 3624.7 & 3624.2 \\
\hline 1963 & 16 & 3905 & 3966.5 & 3911.5 & 3979.6 & 3973.2 & 3971.4 \\
\hline 1964 & 17 & 4235 & 4293.0 & 4333.8 & 4310.8 & 4296.6 & 4291.7 \\
\hline 1965 & 18 & 4535 & 4598.8 & 4658.1 & 4620.3 & 4593.6 & 4583.2 \\
\hline 1966 & 19 & 4805 & 4884.4 & 4964.9 & 4908.5 & 4864.4 & 4845.1 \\
\hline 1967 & 20 & 5065 & 5152.1 & 52454.7 & 5176.3 & 5109.9 & 5077.8 \\
\hline 1968 & 21 & 5305 & 5402.2 & 5528.3 & 5425.1 & 5331.3 & 5282.3 \\
\hline 1969 & 22 & 5515 & 5636.3 & 5786.8 & 5656.1 & 5530.2 & 5459.8 \\
\hline 1970 & 23 & 5665 & 5855.7 & 6030.9 & 5870.8 & 5708.4 & 5612.0 \\
\hline 1971 & 24 & 5785 & 6061.5 & 6261.7 & 6070.4 & 5867.6 & 5740.6 \\
\hline 1972 & 25 & 5895 & 6254.7 & 6480.0 & 6256.2 & 6009.5 & 5847.6 \\
\hline 1973 & 26 & 5995 & 6436.5 & 6686.6 & 6429.3 & 6135.6 & 5934.6 \\
\hline 1974 & 27 & 6085 & 6607.7 & 6882.4 & 6590.8 & 6247.4 & 6003.4 \\
\hline 1975 & 28 & 6170 & 6769.2 & 7068.1 & 6741.8 & 6346.4 & 6055.7 \\
\hline 1976 & 29 & 6240 & 6921.7 & 7244.4 & 6883.0 & 6443.7 & 6093.1 \\
\hline 1977 & 30 & 6300 & 7065.9 & 7411.9 & 7015.2 & 6510.6 & 6117.0 \\
\hline 1978 & 31 & 6350 & 7202.4 & 7571.2 & 7139.3 & 6571.8 & 6128.7 \\
\hline
\end{tabular}


TABLE 9: The actual data and the prediction data of the cumulative production of Bavly [10] oilfield.

\begin{tabular}{|c|c|c|c|c|c|c|c|c|}
\hline \multirow{3}{*}{ year } & \multicolumn{8}{|c|}{ cumulative production (million tons) } \\
\hline & $\mathrm{t}(\mathrm{a})$ & & $\mathrm{T}$ & $\mathrm{L}$ & $\mathrm{G} \& \mathrm{H}$ & $\mathrm{T}$ & $\mathrm{L}$ & $\mathrm{G} \& \mathrm{H}$ \\
\hline & & practical data & prediction data $n=2$ & & & prediction data $n=7$ & & \\
\hline 1959 & 12 & 2450 & 2318.789 & 2500.6 & 2465.9 & 2446.3177 & 2500.6 & 2465.9 \\
\hline 1960 & 13 & 2830 & 2836.9906 & 2843.1 & 2864.3 & 2843.0266 & 2845.2 & 2864.9 \\
\hline 1961 & 14 & 3200 & 3281.8253 & 3186.2 & 3250.6 & 3195.8839 & 3198.9 & 3253.5 \\
\hline 1962 & 15 & 3565 & 3667.8429 & 3520.6 & 3618.8 & 3549.8524 & 3553.6 & 3624.2 \\
\hline 1963 & 16 & 3905 & 4005.9848 & 3841.4 & 3966.5 & 3900.8663 & 3900.9 & 3971.4 \\
\hline 1964 & 17 & 4235 & 4304.637 & 4146.3 & 4293.0 & 4236.546 & 4233.2 & 4291.7 \\
\hline 1965 & 18 & 4535 & 4570.3352 & 4434.4 & 4598.8 & 4547.2328 & 4544.1 & 4583.2 \\
\hline 1966 & 19 & 4805 & 4808.2484 & 4706.0 & 4884.4 & 4827.7119 & 4828.6 & 4845.1 \\
\hline 1967 & 20 & 5065 & 5022.5182 & 4961.5 & 5152.1 & 5076.3844 & 5083.2 & 5077.8 \\
\hline 1968 & 21 & 5305 & 5216.5021 & 5201.7 & 5402.2 & 5294.047 & 5305.6 & 5282.3 \\
\hline 1969 & 22 & 5515 & 5392.9507 & 5427.5 & 5636.3 & 5482.8775 & 5494.9 & 5459.8 \\
\hline 1970 & 23 & 5665 & 5554.1387 & 5639.9 & 5855.7 & 5645.7241 & 5650.8 & 5612.0 \\
\hline 1971 & 24 & 5785 & 5701.9639 & 5839.8 & 6061.5 & 5785.6499 & 5773.9 & 5740.6 \\
\hline 1972 & 25 & 5895 & 5838.0216 & 6028.1 & 6254.7 & 5905.6629 & 5865.2 & 5847.6 \\
\hline 1973 & 26 & 5995 & 5963.6633 & 6205.6 & 6436.5 & 6008.568 & 5926.1 & 5934.6 \\
\hline 1974 & 27 & 6085 & 6080.0409 & 6373.2 & 6607.7 & 6096.8977 & 5958.4 & 6003.4 \\
\hline 1975 & 28 & 6170 & 6188.1426 & 6531.6 & 6769.2 & 6172.8895 & 5963.7 & 6055.7 \\
\hline 1976 & 29 & 6240 & 6288.8208 & 6681.4 & 6921.7 & 6238.4913 & 5944.1 & 6093.1 \\
\hline 1977 & 30 & 6300 & 6382.8148 & 6823.3 & 7065.9 & 6295.3804 & 5901.4 & 6117.0 \\
\hline 1978 & 31 & 6350 & 6470.7689 & 6957.9 & 7202.4 & 6344.9897 & 5837.5 & 6128.7 \\
\hline
\end{tabular}

TABLE 10: Errors.

\begin{tabular}{|c|c|c|c|c|c|c|c|}
\hline & & $\mathrm{T}$ & $\mathrm{L}$ & $\mathrm{G} \& \mathrm{H}$ & $\mathrm{T}$ & $\mathrm{L}$ & G@H \\
\hline year & $\mathrm{t}(\mathrm{a})$ & prediction data $\mathrm{n}=2$ & & & prediction data $\mathrm{n}=7$ & & \\
\hline 1959 & 12 & 0.053556 & 0.020653 & 0.00649 & 0.001503 & 0.020653 & 0.00649 \\
\hline 1960 & 13 & 0.00247 & 0.004629 & 0.01212 & 0.004603 & 0.005371 & 0.012332 \\
\hline 1961 & 14 & 0.02557 & 0.004313 & 0.015813 & 0.001286 & 0.000344 & 0.016719 \\
\hline 1962 & 15 & 0.028848 & 0.012454 & 0.015091 & 0.004249 & 0.003198 & 0.016606 \\
\hline 1963 & 16 & 0.02586 & 0.016287 & 0.015749 & 0.001059 & 0.00105 & 0.017004 \\
\hline 1964 & 17 & 0.016443 & 0.020945 & 0.013695 & 0.000365 & 0.000425 & 0.013388 \\
\hline 1965 & 18 & 0.007792 & 0.022183 & 0.014068 & 0.002697 & 0.002007 & 0.010628 \\
\hline 1966 & 19 & 0.000676 & 0.020604 & 0.016524 & 0.004727 & 0.004912 & 0.008345 \\
\hline 1967 & 20 & 0.008387 & 0.020434 & 0.017196 & 0.002248 & 0.003593 & 0.002527 \\
\hline 1968 & 21 & 0.016682 & 0.019472 & 0.018322 & 0.002065 & 0.000113 & 0.004279 \\
\hline 1969 & 22 & 0.02213 & 0.015866 & 0.021995 & 0.005825 & 0.003645 & 0.010009 \\
\hline 1970 & 23 & 0.01957 & 0.004431 & 0.033663 & 0.003403 & 0.002507 & 0.009356 \\
\hline 1971 & 24 & 0.014354 & 0.009473 & 0.047796 & 0.000112 & 0.001919 & 0.007675 \\
\hline 1972 & 25 & 0.009666 & 0.022578 & 0.061018 & 0.001809 & 0.005055 & 0.008041 \\
\hline 1973 & 26 & 0.005227 & 0.035129 & 0.073645 & 0.002263 & 0.011493 & 0.010075 \\
\hline 1974 & 27 & 0.000815 & 0.047362 & 0.0859 & 0.001955 & 0.020805 & 0.01341 \\
\hline 1975 & 28 & 0.00294 & 0.058606 & 0.097115 & 0.000468 & 0.033436 & 0.018525 \\
\hline 1976 & 29 & 0.007824 & 0.070737 & 0.109247 & 0.000242 & 0.04742 & 0.023542 \\
\hline 1977 & 30 & 0.013145 & 0.083063 & 0.121571 & 0.000733 & 0.06327 & 0.029048 \\
\hline 1978 & 31 & 0.019019 & 0.095732 & 0.134236 & 0.000789 & 0.080709 & 0.03485 \\
\hline
\end{tabular}


the appropriate expansion order $n$ is selected, a new model for the prediction of cumulative production is established. Furthermore, the error of the new model is discussed, and the model can theoretically achieve any given precision.

(2) The analysis of examples of the new model shows that the prediction error gets smaller; the correlation coefficient between predicted and practical data becomes closer to 1 with the increases of the order $n$. Therefore, in order to meet the requirements of accuracy, an appropriate order $n$ should be selected as far as possible. Because of the machine error of computers, the accuracy of prediction may be not ideal with larger order $n$.

(3) Compared with other models in the literatures, the results indicate that the model has higher prediction accuracy. It can be applied to forecast the production of oil and gas fields.

\section{Appendix}

See Tables 5, 6, 7, 8, 9, and 10 .

\section{Abbreviations}

G\&H model: Gompertz model and the Herbert model

T model: $\quad$ Taylor expansion model

L model: logistic model.

\section{Data Availability}

The data used to support the findings of this study are available from the corresponding author upon request.

\section{Conflicts of Interest}

The authors declare that they have no conflicts of interest.

\section{Authors' Contributions}

Xianfeng Ding and Dan Qu conceived and designed the study. Xianfeng Ding performed the MATLAB experiments. Haiyan Qiu wrote the paper. Xianfeng Ding and Dan Qu reviewed and edited the manuscript. All authors read and approved the manuscript.

\section{Acknowledgments}

At the point of finishing this paper, the authors would like to express their sincere thanks to all those who have lent them hands in the course of my writing this paper. First of all, they would like to take this opportunity to show their sincere gratitude to the supervisor, Mr. Xianfeng Ding, who has given so much useful advices on the writing and has tried his best to improve the paper. Secondly, they would like to express their gratitude to their classmates who offered them references and information on time. Without their help, it would have been much harder to finish this paper.

\section{References}

[1] J. J. Arps, "Analysis of decline curies," SPE-G, 1945.

[2] J. J. Arps, "Estimation of primary oil reserves," SPE 627-G, 1956.

[3] R. W. Gentry, "Decline-curve analysis," SPE 3365-PA, 1972.

[4] M. J. Fetkovich, "Decline curve analysis using type curves," SPE 4629-PA, 1980.

[5] Y. C. Chen, "The derivation and application of Weng's prediction model," Research Institute of Petroleum Exploration and Development of CNPC, vol. 16, no. 2, pp. 22-26, 1996.

[6] Y. D. Hu, "Exponential distribution and inverse tangential distribution of production decline," Applied Mathematics \& Information Sciences, vol. 24, no. 6, pp. 76-81, 1997.

[7] Q. T. Yu, "A new decline curve," Petroleum Exploration and Development, vol. 26, no. 3, pp. 72-75, 1999.

[8] C. Z. Song and X. J. Ma, "Generalized Weibull, Wengcycle model for predicting oil and gas production," Mineral Rock, vol. 20, no. 2, pp. 37-38, 2000.

[9] C. L. Li, S. G. Han, and L. S. Cheng, "Research on a new production decline curve," Journal of Southwest Petroleum Institute, vol. 25, no. 5, pp. 31-33, 2003.

[10] X. F. Ding and Z. B. Liu, "A new model for oil and gas production prediction," Petroleum Exploration and Development, vol. 31, no. 3, pp. 104-106, 2004.

[11] Y. J. Zhu and W. J. Gao, "Establishment and research of a new generalized production decline equation," Fault Block Oil and Gas Fields, vol. 12, no. 6, pp. 47-49, 2005.

[12] J. M. Yao, Y. U. Bing-Song, and C. B. Che, "Application of modified GM model in prediction of oil production in Tarim Basin," Petroleum Geology and development in Daqing, vol. 26, no. 1, pp. 92-96, 2007.

[13] F. Zhou, "History matching and production prediction of a horizontal coalbed methane well," Journal of Petroleum Science and Engineering, no. 10, pp. 96-97, 2012.

[14] K. Li and R. N. Horne, "Comparison and verification of production prediction models," Journal of Petroleum Science and Engineering, vol. 55, no. 3-4, pp. 213-220, 2007.

[15] X. Li, C. W. Chan, and H. H. Nguyen, "Application of the Neural Decision Tree approach for prediction of petroleum production," Journal of Petroleum Science and Engineering, vol. 104, pp. 11-16, 2013.

[16] T. A. Saraiva, A. Szklo, A. F. P. Lucena, and M. F. ChavezRodriguez, "Forecasting Brazil's crude oil production using a multi-Hubbert model variant," Fuel, vol. 115, pp. 24-31, 2014.

[17] R. R. Charpentier and T. A. Cook, "Improved USGS methodology for assessing continuous petroleum resources using analogs," US Geological Survey Open-File Report, vol. 1309, no. 27, 2010.

[18] W. W. Weiss, R. S. Balch, and B. A. Stubbs, "How artificial intelligence methods can forecast oil production," SPE-75143MS, 2002.

[19] T. Insperger, "On the approximation of delayed systems by Taylor series expansion," Journal of Computational and Nonlinear Dynamics, vol. 10, no. 2, Article ID 024503, 2015.

[20] H. Min, W. Jia, Y. Zhao, W. Zuo, H. Ling, and Y. Luo, "LATE: a level-set method based on local approximation of Taylor expansion for segmenting intensity inhomogeneous images," IEEE Transactions on Image Processing, vol. 27, no. 10, pp. 50165031, 2018.

[21] W. Yonthanthum, A. Rattana, and M. Razzaghi, "An approximate method for solving fractional optimal control problems 
by the hybrid of block-pulse functions and Taylor polynomials," Optimal Control Applications and Methods, vol. 39, no. 3, pp. 873-887, 2018.

[22] A. Nadh, J. Samuel, A. Sharma, S. Aniruddhan, and R. K. Ganti, "A Taylor Series Approximation of Self-Interference Channel in Full-Duplex Radios," IEEE Transactions on Wireless Communications, vol. 16, no. 7, pp. 4304-4316, 2017.

[23] S.-J. Lee, M.-C. Kang, K.-H. Uhm, and S.-J. Ko, "An edge-guided image interpolation method using Taylor series approximation," IEEE Transactions on Consumer Electronics, vol. 62, no. 2, pp. 159-165, 2016.

[24] Y. Q. Chen, J. G. Hu, and D. J. Zhang, "Derivation of logistic model and its self-regression method," Xinjiang Petroleum Geology, vol. 17, no. 2, pp. 150-155, 1996.

[25] J. G. Hu, D. J. Zhang, and Y. Q. Chen, "A model investigation on forecasting the production of oil and gas field," Natural Gas Industry, vol. 17, no. 5, pp. 31-34, 1997.

[26] Q. T. Yu, "A current formula of generalized increase and decline curves for predicting oilfield development indexes," Petroleum Exploration and Development, vol. 27, no. 1, pp. 50-53, 2000.

[27] J. G. Hu and Y. Q. Chen, "A simple model for predicting oil and gas field production," China Offshore Oil and Gas, vol. 9, no. 1, pp. 53-59, 1995.

[28] T. Ji, S. Lu, M. Tang et al., "Application of BP neural network model in fracturing productivity prediction of fuyu tight oil reservoir in jilin oilfield," Acta Geologica Sinica, vol. 89, no. s1, pp. 154-155, 2015. 


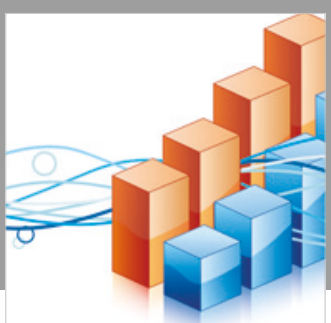

Advances in

Operations Research

\section{-n-m}
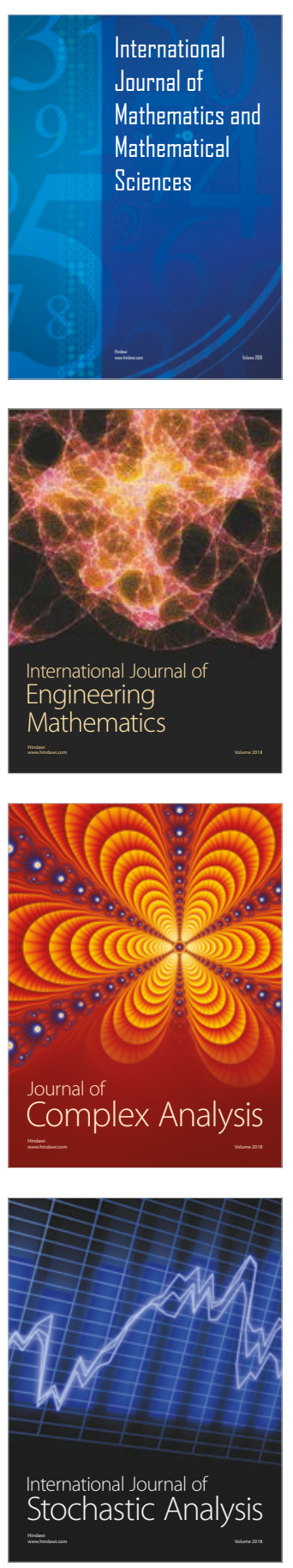
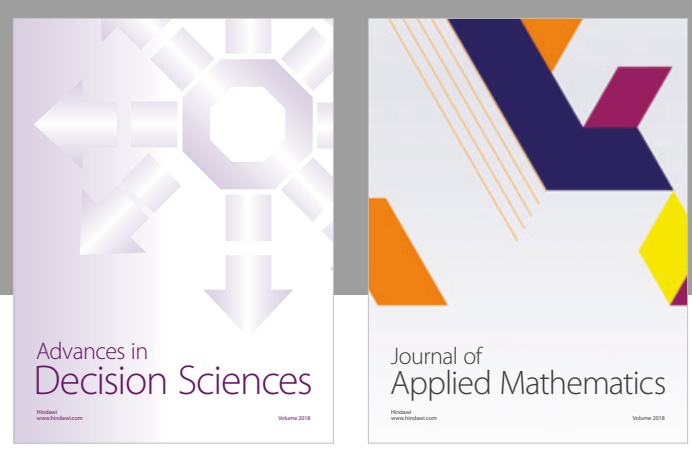

Journal of

Applied Mathematics
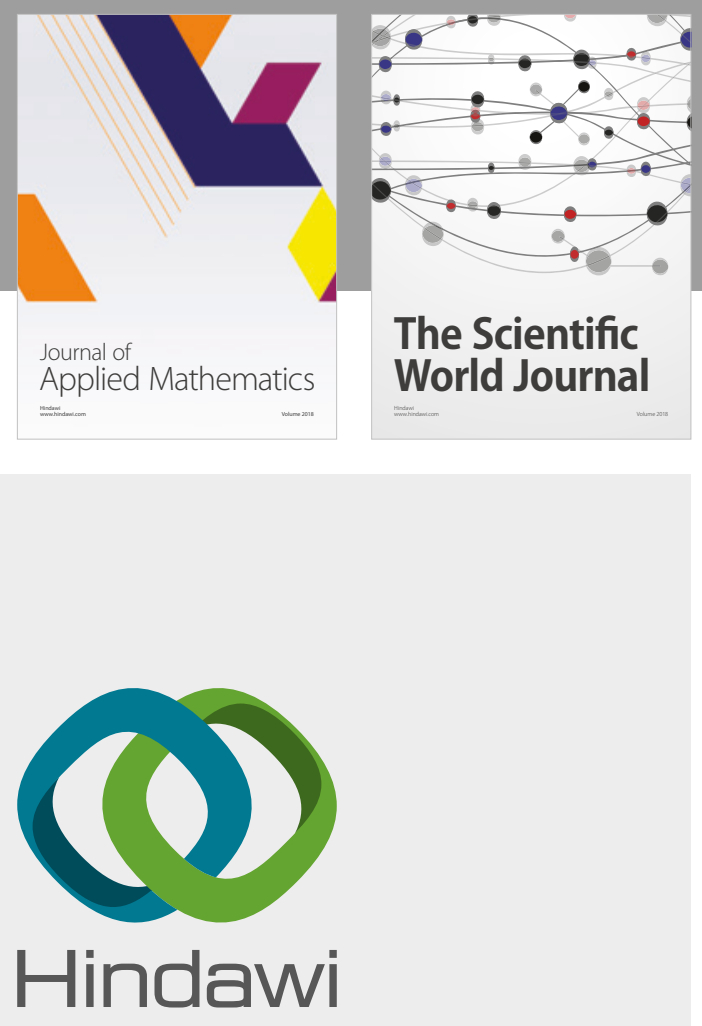

Submit your manuscripts at

www.hindawi.com

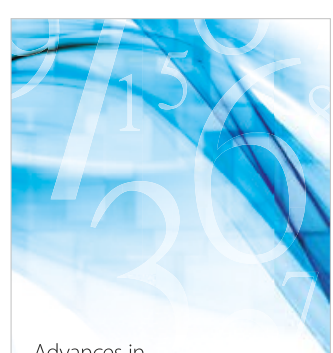

Advances in
Numerical Analysis
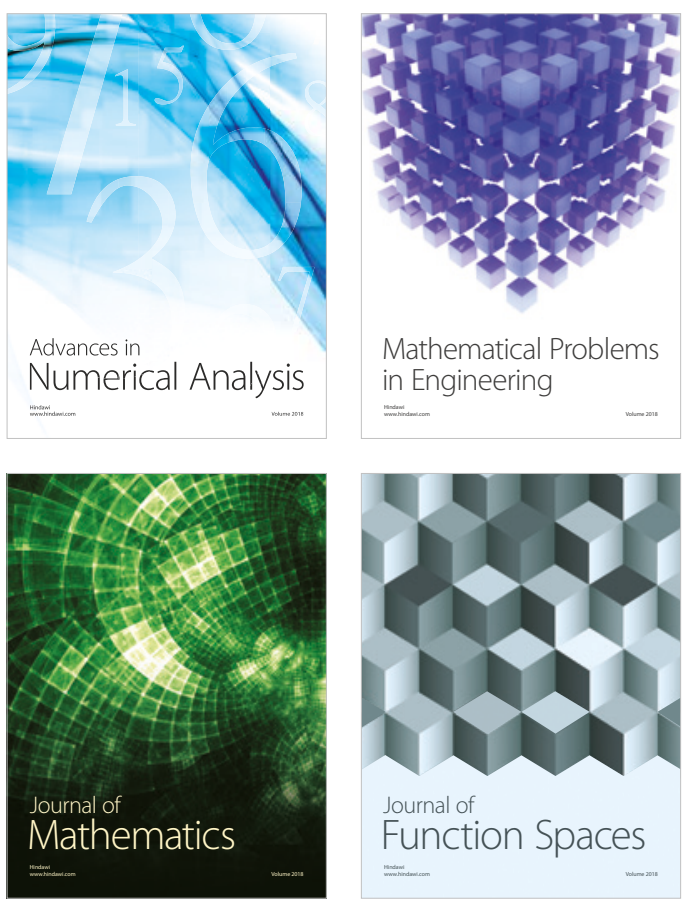

Mathematical Problems in Engineering

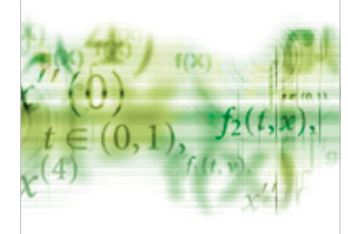

International Journal of

Differential Equations

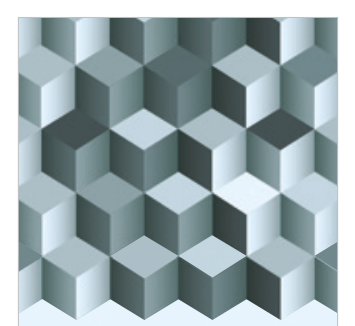

Journal of

Function Spaces

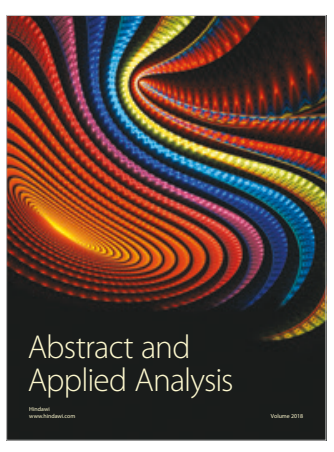

The Scientific

World Journal

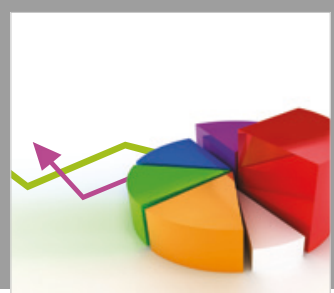

Journal of

Probability and Statistics
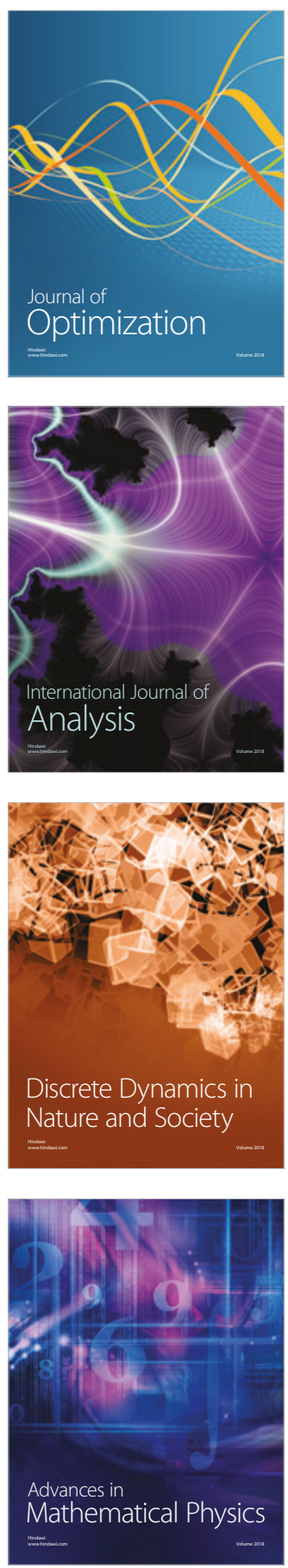